\title{
High-energy X-ray scattering studies on the formation of calcium phosphates in the presence of heavy metals
}

Olaf J. Borkiewicz

X-ray Science Division, Advanced Photon Source

Argonne National Laboratory

Due to increasing risk associated with the contamination of the environment with heavy metals and radionuclides, society worldwide is facing a pressing need for new more efficient environmental remediation techniques. One of the approaches that gained considerable attention over the last two decades is in situ metal stabilization by phosphate amendments - a technique based on the co-precipitation of contaminant species with phosphates and the formation of insoluble metal-substituted minerals, such as apatite $\mathrm{Ca}_{5-\mathrm{x}} \mathrm{M}_{\mathrm{x}}\left(\mathrm{PO}_{4}\right)_{6}(\mathrm{OH}, \mathrm{Cl}, \mathrm{F})$. Formation of apatite at Earth-surface conditions however, is preceded by crystallization of other less stable calcium phosphates (precursors) that ultimately transform to apatite. This important aspect of apatite formation has not been addressed in the context of heavy metal sequestration. This study attempts to fill a gap in our understanding of the connection between the formation of apatite precurors and co-precipitation of contaminant species with apatite under Earth-surface conditions. Early stages of crystallization and pathways of calcium phosphates development in the presence of a suite of metal cations under Earth-surface conditions were studied using in situ time-resolved X-ray diffraction and total X-ray scattering. High-energy X-ray diffraction data have been collected at beamline 11-ID-C and total X-ray scattering data suitable for PDF analyses have been collected at PDF-dedicated beamline 11-ID-B, both at the Advance Photon Source, Argonne National Laboratory.

The results clearly indicate a significant influence of contaminant species on the pathways of phase development in the $\mathrm{Ca}(\mathrm{OH})_{2}-\mathrm{H}_{3} \mathrm{PO}_{4}-\mathrm{H}_{2} \mathrm{O}$ system under environmental conditions. Finding reported herein have critical bearing on the efficiency of metal stabilization by phosphate amendment and emphasize the need of careful consideration and cautious proceeding in the attempts to apply phosphate amendments to immobilize heavy metals in the environment. 